\title{
Desafios do Ensino de Psicologia Clínica em Cursos de Psicologia
}

Challenges found in the teaching of clinical Psychology in the Psychology courses

Desafíos de la enseñanza de Psicología clínica en cursos de Psicología

Ively Guimarães Abdalla, Sylvia

Helena Batista \&

Nildo Alves Batista

Universidade

Federal de São Paulo
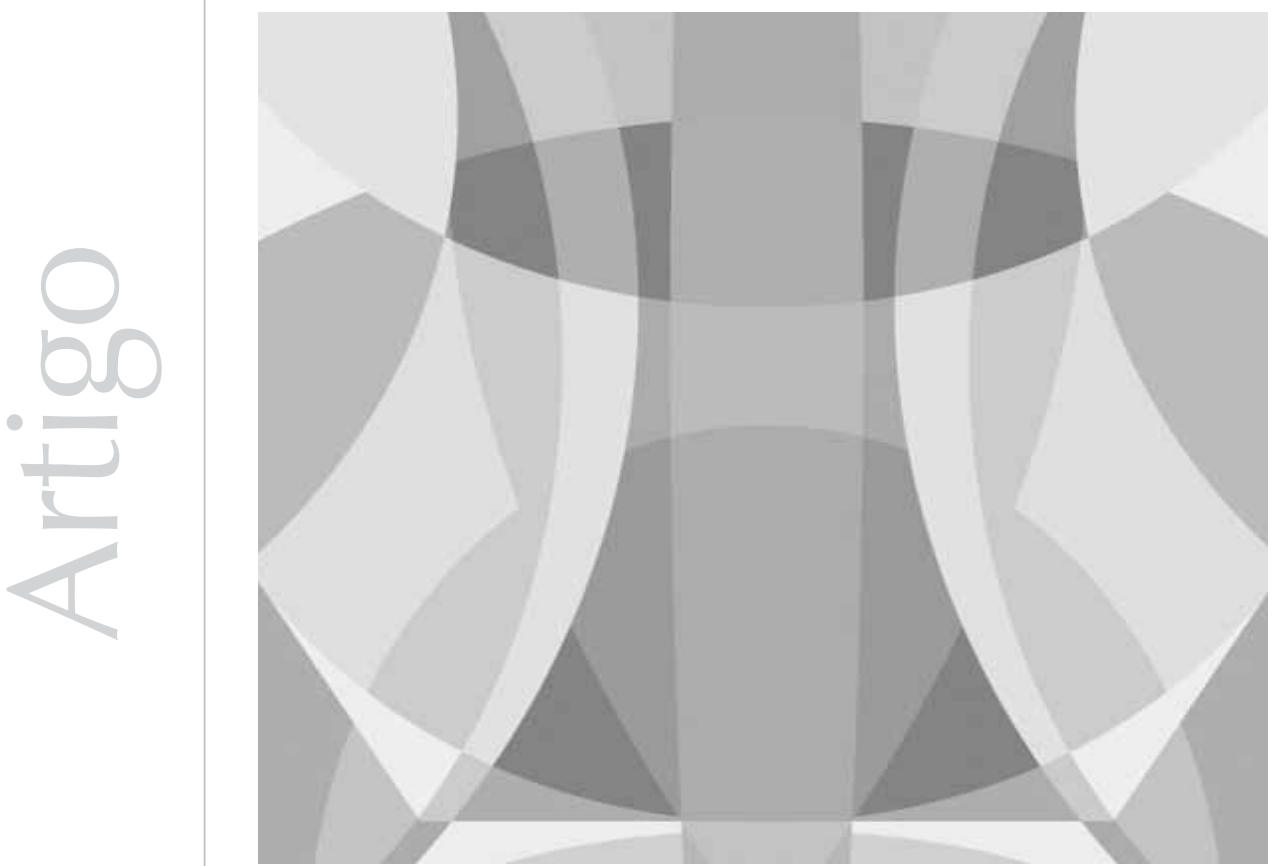
Resumo: Este artigo analisa os desafios e as dificuldades do ensino de Psicologia clínica em cursos de graduação em Psicologia a partir de dados coletados em pesquisa realizada na Universidade Federal de São Paulo (Unifesp). Nota-se que a preparação para o exercício profissional deve ser desenvolvida pela maior articulação entre o arcabouço teórico para esse fazer profissional e a realidade em que o aluno irá atuar. Tomar a prática como eixo estruturante possibilita ao aluno aprender numa situação real com o cliente. Os sujeitos percebem a necessidade de mudanças na formação do psicólogo clínico. Os dados apontam a necessidade de reformulações curriculares que vão ao encontro do movimento que ocorre no ensino de Psicologia clínica, em que a práxis deve voltar-se para a articulação entre a clínica e o social. O novo profissional necessita compreender a clínica a partir de referenciais teóricos que contemplem a noção de subjetividade como resultante de uma construção social e histórica.

Palavras-chave: Ensino de psicologia. Psicologia clínica. Currículo. Características do professor.

Abstract: The aim of this study is to analyze the challenges and difficulties found in the teaching of clinical psychology in the psychology undergraduation courses, based on the data collected in a research carried out in the Universidade Federal de São Paulo (UNIFESP). It was observed that the professional practice must be developed based on the articulation between the theoretical content and the reality where the student will work. The practice as a structural axis allows the student to learn in a real situation established with the patient. Individuals realize the need of changes in the conception of the clinical psychologist education. Data showed that the need of new curricular guidelines is in accordance with the change that happens now in the clinical psychology teaching, that points out that praxis must aim the articulation between the clinical practice and the social life. The professional nowadays needs to understand this clinical practice based on the theoretical referentials, which have subjectivity as a result of the social and historical construction.

Keywords: Psychology teaching. Clinical psychology. Curriculum. Professor characteristics.

Resumen: Este artículo analiza los desafíos y las dificultades de la enseñanza de Psicología clínica en cursos de graduación en Psicología desde datos colectados en pesquisa realizada en la Universidad Federal de Sao Paulo (Unifesp). Se nota que la preparación para el ejercicio profesional debe ser desarrollada por la mayor articulación entre el abarque teorético para ése hacer profesional y la realidad en la que el alumno actuará. Tomar la práctica como eje estructurante posibilita al alumno aprender en una situación real con el cliente. Los sujetos perciben la necesidad de cambios en la formación del psicólogo clínico. Los datos señalan la necesidad de reformulaciones curriculares que van al encuentro del movimiento que ocurre en la enseñanza de Psicología clínica, en que la práctica debe volverse a la articulación entre la clínica y lo social. El nuevo profesional necesita comprender la clínica desde referenciales teóricos que contemplen la noción de subjetividad como resultante de una construcción social e histórica.

Palabras-clave: Enseñanza de psicología. Psicología clínica. Currículo. Características del maestro.

O ensino superior, após a promulgação da LDB/96 e das Diretrizes Curriculares Nacionais (DCN) para os cursos de graduação, atravessa um momento de transição que se reflete num movimento de reformulação dos currículos dos diversos cursos de formação superior no País. Isso tem ocorrido também com o ensino de graduação em Psicologia, que, após a homologação das suas Diretrizes Curriculares Nacionais ([DCN], Brasil, 2004), procura buscar sintonia e organicidade com as políticas públicas e as necessidades sociais.

Por essas DCNs (Brasil, 2004), o curso de graduação de Psicologia deve ter como meta central a formação do psicólogo voltada para a atuação profissional, para a pesquisa e para o ensino de Psicologia, e essa formação, segundo seu artigo $4 \stackrel{\circ}{\circ}$, deve ter como objetivo geral dotar o profissional dos conhecimentos requeridos para o exercício das seguintes competências e habilidades gerais: atenção à saúde, tomada de decisões, comunicação, liderança, administração e gerenciamento e educação permanente.

Como a Psicologia é uma ciência com uma gama muito variada de orientações teóricometodológicas, práticas e contextos de inserção profissional, as diretrizes destacam que a formação nessa área deve ser realizada em torno de ênfases curriculares "entendidas 
Paparelli e NogueiraMartins (2007) reconhecem que não há mais espaço para a idéia da Psicologia clínica reduzida, exclusivamente, ao espaço do consultório privado. como um conjunto delimitado e articulado de competências e habilidades que configuram oportunidades de concentração de estudos e estágios em algum domínio da Psicologia" (Brasil, 2004, Art. 10, p. 4). Assim, as diferentes instituições que ministram o curso de graduação têm autonomia de escolha sobre as orientações teóricometodológicas que embasarão a formação do futuro profissional da área. Um dos focos da formação do psicólogo, segundo as DCN, é que as atividades acadêmicas devem aproximar o formando do exercício profissional correspondente às competências previstas para a sua formação.

Outro aspecto que tem gerado muitas discussões no momento é o fato de a Psicologia passar a ser considerada uma das profissões da área da saúde. Isso, na atualidade, é marcado pelo fato de o Ministério da Educação e o Ministério da Saúde estarem trabalhando de forma articulada com o objetivo de que os futuros profissionais psicólogos possam atuar no Sistema Único de Saúde prestando serviços voltados à atenção da saúde da população brasileira.

A Psicologia, no entanto, apesar de pertencer à área da saúde, possui muitas outras dimensões para a constituição de sua prática, como a atuação na área da educação, do trabalho, das organizações, do meio ambiente, etc.

A Associação Brasileira de Ensino de Psicologia (ABEP) salienta que essa inclusão dos psicólogos no SUS é um ganho para a formação dos alunos desse curso, porém trata-se de uma conquista a ser ainda implementada.

Spink (Coord.), Bernardes e Menegon (2006) destacam a necessidade de "potencializar a mudança na graduação a partir da reflexão crítica sobre as experiências na prática da
Psicologia no SUS e sobre nossa produção relacionada com a saúde pública" (p. 68).

A partir dessa nova compreensão sobre a inserção da Psicologia na área da saúde e da atual concepção sobre o objeto dessa ciência, Paparelli e Nogueira-Martins (2007) reconhecem que não há mais espaço para a idéia da Psicologia clínica reduzida, exclusivamente, ao espaço do consultório privado. Os autores comentam que devemos refletir sobre a contextualização da clínica e sobre o ato clínico,

o qual deve ser orientado por um conhecimento mais amplo do indivíduo em seu desenvolvimento e em sua realidade pessoal, nos quais está envolvido, também, o entendimento do contexto da saúde pública e do contexto institucional do trabalho (Silva, 1992; Lo Bianco et al., 1994); além disso, vale ressaltar que essa forma de atuar e "ser psicólogo" está permeada por uma postura ética, na qual existe implicada a noção de sujeito constituído e tomado a partir de um contexto. (p. 3)

Nesse sentido, a atual concepção do objeto da Psicologia clínica implica uma nova construção do exercício da prática profissional, na qual teremos que buscar relações entre a realidade social, a atuação profissional e o conhecimento de Psicologia, além de atender à demanda por um psicólogo que desenvolva sua prática vinculando finalidades, objetivos, instrumentos, teorias, técnicas e necessidades sociais que se articulem num projeto de trabalho inserido em equipe multiprofissional.

As reflexões dos autores vão ao encontro do pensamento de Dutra (2004), que situa as práticas clínicas imbricadas com o contexto social, o que faz com que o profissional busque "uma articulação mais concreta entre a clínica e o social" (p. 382). Dessa 
maneira, essa nova práxis inclui uma análise do contexto em que o sujeito está inserido.

Gioia-Martins e Rocha Junior (2001), ao analisarem especificamente a Psicologia clínica, discutem os limites e as possibilidades dessa área na atualidade e comentam sobre a necessidade de se pensar sobre a função social do psicólogo, pois a saída de suas clínicas privadas traz um aumento do interesse pela área da saúde.

Para Ferreira Neto e Penna (2006), a discussão sobre a clínica se desloca da epistemologia para a ética, pois deve ser compreendida "menos como um modo de intervenção e mais como um dispositivo produtor de subjetividade... como um dispositivo ético de subjetivação" (p. 382).

Essas novas concepções que embasam a prática da clínica têm conseqüências no enfoque teórico desenvolvido na formação dos psicólogos clínicos na graduação, que, ao escolherem essa área, devem adotar referenciais teóricos que contemplem a noção de subjetividade como resultante de uma construção social e histórica, o que era até então pouco pensado na Psicologia clínica

Para Ferreira Neto e Penna (2006), a discussão sobre a clínica se desloca da epistemologia para a ética, pois deve ser compreendida "menos como um modo de intervenção e mais como um dispositivo produtor de subjetividade... como um dispositivo ético de subjetivação" (p. 382). tradicional (Dutra, 2004).

Este artigo propõe-se a discutir os desafios e as dificuldades do ensino de Psicologia clínica em cursos de graduação em Psicologia, que é um dos núcleos temáticos da tese "O ensino de Psicologia clínica na graduação: uma análise a partir de psicólogos clínicos docentes e não docentes" desenvolvida no programa de pós-graduação Ensino em Ciências da Saúde, da Unifesp. Os dados aqui discutidos foram coletados a partir de depoimentos de psicólogos em atividade clínica, docentes e não docentes, e analisados através da técnica de análise temática.

\section{Metodologia}

Foi realizada uma pesquisa qualitativa partindo-se da premissa de que essa abordagem permitiria um levantamento exaustivo de dados sobre as concepções de psicólogos clínicos, docentes e não docentes, sobre o ensino de Psicologia clínica na graduação em Psicologia.

A amostra foi composta por 20 psicólogos, docentes e não docentes, escolhidos de forma intencional, tendo por referência a hipótese de que, nessas diferentes categorias, incluir-seiam distintas oportunidades de aproximação à questão do ensino da Psicologia clínica.

Com relação ao tempo de exercício na prática clínica, procuramos garantir que houvesse maior variabilidade, pois esperávamos que essa pudesse abranger diferentes experiências.

Os sujeitos foram contatados pessoalmente. Numa primeira aproximação, procedeu-se ao esclarecimento sobre a pesquisa e sobre como seria sua participação, ressaltando-se que, a qualquer momento, poderiam retirar seu consentimento.

O instrumento de coleta de dados utilizado foi uma entrevista semi-estruturada, na qual foram explorados as dificuldades do ensino de Psicologia clínica na graduação e os desafios para seu aprimoramento. As entrevistas foram gravadas, com o consentimento dos sujeitos; a média de duração foi de 50 minutos aproximadamente, e todas foram transcritas na íntegra.

A análise dos dados foi realizada através de uma das técnicas de análise de conteúdo, denominada análise temática, com o objetivo de atingir os significados manifestos e latentes. Segundo Minayo (1992), essa abordagem metodológica possibilita que os valores de referência e os modelos de comportamento presentes no discurso sejam caracterizados pela presença de determinados temas.

Para a mesma autora,

Fazer análise temática consiste em descobrir os núcleos de sentido que compõem uma comunicação cuja presença ou freqüência 
signifiquem alguma coisa para o objetivo analítico visado. Ou seja, tradicionalmente, a análise temática se encaminha para a contagem de freqüência das unidades de significação como definitórias do caráter do discurso. (1999, p. 209)

A partir dos núcleos direcionadores da entrevista (dificuldades do ensino de Psicologia clínica na graduação e os desafios para seu aprimoramento), a análise de conteúdo compreendeu as seguintes etapas, como sugere Franco (2003): leitura seletiva do material coletado, organização das respostas dos diferentes entrevistados, seleção dos depoimentos e identificação de unidades de contexto, ou seja, partes mais amplas do discurso nas quais são identificadas as unidades de registro sobre sentidos e de significados implícitos nas comunicações orais, escritas e simbólicas. A análise dessas unidades de registro, reconhecendo as convergências e divergências nas "falas" dos sujeitos, permitiu a apreensão das categorias emergentes do campo analisado.

\section{Resultados e discussão}

A análise temática das entrevistas com relação às dificuldades e aos desafios do ensino de Psicologia clínica na graduação apontadas pelos psicólogos identificou 33 unidades de contexto, das quais emergiram 52 unidades de registro. Nessas unidades, pudemos identificar quatro grandes categorias: "complexidade e abrangência da Psicologia e seu objeto", "proposta curricular", "orientação docente aos alunos" e "perfil do aluno de Psicologia".

Essas categorias aparecem tanto nos discursos dos psicólogos docentes como dos não docentes.

As falas que ilustram essas categorias são apresentadas no texto identificadas com as letras $\mathrm{P}$ e $\mathrm{D}$, respectivamente para os psicólogos não docentes e docentes.

Observamos que os docentes aprofundam mais a análise sobre a "complexidade e a abrangência da Psicologia e seu objeto" e a "proposta curricular" como fatores que dificultam o ensino da Psicologia clínica. Acreditamos que, por estarem inseridos nas instituições educacionais e, em conseqüência, mais próximos das discussões sobre a reforma do ensino superior, estejam mais esclarecidos sobre os movimentos de transformações paradigmáticas por que passa o ensino superior, especialmente o ensino de Psicologia na graduação.

Em contrapartida, na categoria "orientação docente aos alunos", a maior contribuição vem por parte dos psicólogos não docentes, o que pode, talvez, indicar uma dificuldade de auto-avaliação sobre sua prática educacional pelos psicólogos docentes.

A complexidade e a abrangência do campo da Psicologia que estuda um objeto que, pela sua natureza, é subjetivo, implica um desafio para o ensino dessa ciência e para a formação dos alunos com relação ao seu exercício profissional, na visão dos psicólogos: "Penso que as dificuldades são muito substantivas, da própria constituição teórica que vai nortear o que são possibilidades de atuar. A dificuldade é grande pela diversidade e pelas fronteiras desse entendimento" (D 6).

Essas dificuldades vão ao encontro dos estudos de Aguirre et al. (2000), de GioiaMartins e Rocha Junior (2001), Dutra (2004), Ferreira Neto e Penna (2006), e Paparelli e Nogueira-Martins (2007).

A "especificidade do objeto da Psicologia clínica" é apontada, especialmente pelos docentes, como uma subcategoria relevante de dificuldades no ensino dessa área, e envolve tanto aspectos técnicos como éticos.

Quando você está com a alma quebrada, o seu coração está partido, como que é isso? Isso é um objeto de atuação clínica. Só porque alguém fala que está com o coração partido, se alguém na fala é um 
objeto, aí é uma questão muito grande da própria fronteira do próprio objeto. Assim, qual o objeto na situação clínica?

É fazendo que se aprende, e esse é um fazer delicadíssimo, porque o fazer ensina a alma do outro, junto da alma do outro. Então há uma questão ética aí envolvida e técnica também. (D6)

A constatação de que o objeto da Psicologia envolve não somente aspectos técnicos mas também aspectos éticos é discutida por Ferreira Neto e Dias Penna (2006). Segundo os autores, a partir da promulgação das DCN de Psicologia, a tradição curricular estruturada em disciplinas é substituída por diretrizes baseadas em competências e habilidades profissionais. Nesse sentido, a formação passa a ser compreendida "como um processo de subjetivação, na medida em que o produto final não é puramente cognitivo..., mas visa a uma transformação dos indivíduos" (p. 387). Essa nova forma de compreender a formação dos alunos leva a uma nova constatação, pois agora precisamos "descrever a produção das subjetividades almejadas" (p. 387).

Essa concepção implica uma transformação da atitude clínica, que deve se deslocar do campo da epistemologia para o da ética, pois a clínica, pelos resultados da pesquisa dos autores,

é um lugar que provoca angústia, na medida em que não há neutralidade possível: o terapeuta participa dessa atividade com sua pessoa. O que ele diz tem uma importância sensível para o paciente, e ambos são afetados por essa experiência, daí a importância da ética do cuidado, na medida em que nessa prática ele é afetado ... sem, no entanto, poder confundir suas próprias questões e vivências com as que o paciente lhe traz. (p. 387)

A especificidade do objeto da Psicologia clínica demanda, na visão dos entrevistados, um processo de autoconhecimento do aluno em formação. "As pessoas que vão fazendo isso há muito tempo falam que a gente só vai conseguir estar trabalhando nisso se ficar constantemente olhando para dentro de si" (D6).

Para um dos docentes entrevistados, é necessário que os alunos da área de clínica sejam "adestrados" para o exercício desse papel.

Existem pequenas ações para aumentar essa capacidade de presença com o outro, de estar com o outro, o que alguns autores chamam de acolhimento supramoral, que é estar com o outro sem ter um julgamento moral, estar com o outro sem a lógica do certo ou errado, do bom e do mau, do sim e do não, como fazer isso. Você aceitá-lo do jeito que ele é, sem querer que as suas coisas se misturem com as dele. Isso é muito difícil, porque exige adestramento. (D1)

Aguirre et al. (2000) comentam que os conhecimentos teóricos desenvolvidos no curso são internalizados "e processados em uma psicoterapia pessoal que torne possível o conhecimento do mundo interno e a utilização dos recursos pessoais na... compreensão dos processos psíquicos" (p. 4).

O "adestramento" a que um dos docentes se refere é percebido como a necessidade de os alunos serem formados como psicólogos clínicos pelos docentes, dentro das tendências emergentes discutidas por Lo Bianco et al. (1994). Essas tendências apontam práticas clínicas menos preocupadas com o intrapsíquico e mais preocupadas com o contexto social. Para Dutra (2004), o sujeito, nesse novo fazer clínico, deve ser visto em seu contexto social. Isso faz, em conseqüência, com que o espaço do referencial teórico deixe de ser o principal norteador da prática, "que passa a ser ocupada pelo compromisso ético do psicólogo" (p. 382). Isso tem implicações nas próprias concepções de sujeito e objeto dessa área da Psicologia, o que envolve modificações nos referenciais teóricos que embasam a prática clínica. 
A proposta curricular dos cursos de graduação é apontada, tanto pelos psicólogos docentes como pelos não docentes, como fator que dificulta o ensino da Psicologia clínica:

\begin{abstract}
No curso, você dá as técnicas, as formas de atuação. Mas o mais importante são os encontros com os pacientes, com a comunidade onde o aluno vai atuar, por isso pode-se aproximá-lo a partir de diferentes experiências, como programas de extensão com os quais ele pode aprender a fazer observação, ir a campo com alunos de diferentes cursos da área da saúde para poder vivenciar um trabalho multiprofissional, aprender a fazer entrevistas, anamnese. Existem várias atividades que o aluno principiante pode fazer sem ferir o nosso código de ética. (D9)
\end{abstract}

A "carga horária" reduzida nas atividades práticas de estágio é uma dificuldade que encontram com relação à sua formação para o exercício prático da profissão.

\begin{abstract}
A gente tem aqueles quatro núcleos que todo mundo tem para ter uma noção em educação, trabalho, saúde, clínica. A gente faz dois núcleos por semestre, duas instituições trabalhando um semestre, então, na hora que a gente começa a engrenar no estágio já acabou, aí a gente já muda de novo, não dá para aprender direito. (P 1)
\end{abstract}

A limitação do tempo de "vivência prática com o paciente" não permite que o aluno compreenda, desenvolva e aprenda o papel que o psicólogo clínico deve desenvolver no atendimento terapêutico.

Na parte referente aos estágios, o aluno vai aprender um semestre. A maioria dos cursos, hoje, está organizada de modo tal que o aluno atende um cliente por semestre, então não posso, por exemplo, formar um psicólogo clínico que vai atender durante dez anos. Tem que tentar resolver isso. (D3)

A pouca carga horária de atividade prática no curso leva, segundo os entrevistados, a uma fragilidade no seu processo de formação.
Essa constatação sobre a importância de o aluno aumentar sua vivência prática no curso para que sua formação seja fortalecida vai ao encontro das DCNs de Psicologia quando estas propõem que as atividades acadêmicas devem aproximar o formando do exercício profissional correspondente às competências previstas para a prática.

Para alguns, a "inadequação de inserção e desenvolvimento de conteúdos teóricos e práticos" dificulta o aprendizado: "O trabalho de conclusão de curso não tinha que ser no último ano. O tempo fica muito tumultuado, com esse trabalho de conclusão de curso" (P1). "Em termos de preparação para poder atender, de me tornar uma profissional, de ter técnicas para poder aplicá-las no meu trabalho, essas questões não foram abordadas" (P4).

Lacunas importantes de conteúdo são apontadas na proposta curricular. Para alguns, isso dificulta as escolhas de atuação, em função do leque de opções para a inserção do psicólogo no mercado de trabalho: "Toda a parte neuropsicológica, o desenvolvimento neurológico de uma forma mais competente, faltou toda a parte de diagnóstico. Não teve a parte hospitalar" (D10). "Faltou um pouco mais de noções de cidadania, e essa coisa mais política" (P5).

Ainadequação de inserçãoe de desenvolvimento de conteúdos gera lacunas importantes no currículo, e isso influencia no modo como irá se desenvolver a formação do aluno. Batista (2004) afirma que o ensino deve ser planejado em função da meta que queremos atingir, isto é, do resultado que queremos obter. Segundo o autor, ao planejarmos o currículo, devemos romper com os problemas que já foram detectados nos modelos tradicionais e nos guiar pelas diretrizes curriculares da área da saúde, que é onde a Psicologia está inserida. Assim, ao selecionarmos os conteúdos que irão compor nosso curso devemos pensar que eles englobam "tudo aquilo que 
integra o programa educativo, incluindo conhecimentos, habilidade e atitudes" (p. 43).

Para Zabala (2002), a forma como se apresentam e são organizados os conteúdos é o que mais influencia o processo de aprendizagem dos alunos. Isso vai ao encontro da fala dos entrevistados, que sentem que, pela inadequação de conteúdos, a formação do aluno de Psicologia pode se apresentar fragilizada.

A "pouca articulação entre teoria e prática" que existe em alguns cursos contribui para que os alunos se sintam menos seguros e preparados para sua inserção na prática.

Quando a gente tem essa interação de programa teórico com os núcleos, a gente vê como trabalhar melhor essa separação que tem entre a teoria que é dada no início do curso e a prática que você vai ver só no final. Dá uma visão de que só depois de muito tempo você vai entender como utilizar. (P1)

Esse enfoque tradicional, de inserir no curso primeiro a teoria e depois a prática, faz com que a inserção tardia do aluno na prática dificulte o processo de ele, na sua aprendizagem, trazer a teoria para sua atuação clínica e compreender o desenvolvimento do processo clínico.

No 1으, 2o e 3ㅇano, a gente tem todo o embasamento teórico. Só hoje, quando a gente começa a ir para a prática, é que todos aqueles conceitos que no começo não faziam muito sentido, porque eram muito abstratos, começam a ter significado. Quando a gente começa a ter um pouco mais de contato com a realidade mesmo, que a gente começa a entender. (P1)

Com a reorganização da ciência e das relações de trabalho, Batista, Batista, \& Goldenberg (2005) afirmam que surgem novas formas de compreensão do que seja educar o homem, conscientizando-nos para "a necessidade de se investir em práticas educativas que tenham na participação crítico-reflexiva um pilar fundamental" (p. 232). Para os autores, esse novo olhar relativo à forma de ensinar e aprender implica desafios para a formação dos profissionais da saúde, em que as dimensões problematizadoras podem assumir "a construção do conhecimento como traço definidor da apropriação de informações e explicação da realidade, tomando-a como ponto de partida e chegada do processo de aprendizagem" (p. 232).

Pelo distanciamento entre teoria e prática no início do curso, os conceitos aprendidos tornam-se pouco significativos. Por outro lado, o enfoque disciplinar e, como conseqüência, a compartimentalização de conteúdos tem, historicamente, favorecido uma fragmentação de conceitos, dicotomias teórico-metodológicas e redução da realidade às disciplinas isoladas. Esses processos expressam-se não só nas atividades acadêmicas cotidianas (ensino, pesquisa e extensão) mas também na organização do trabalho na universidade.

A falta de integração dificulta o "entendimento do exercício da prática" e reflete-se na performance do aluno no atendimento clínico.

Penso que é muito difícil você formar um aluno para a prática quando ele só vai ver um paciente de verdade no último ano do curso. Por isso, penso que um grande desafio para a clínica é aproximar esse aluno da prática desde cedo, isto é, antecipar sua ida a campo para que ele comece a vivenciar seu papel de futuro psicólogo. (D9)

A estruturação da proposta curricular pode ser influenciada diretamente, conforme os entrevistados, pela "cultura institucional". Essa cultura pode possibilitar o atendimento em somente uma linha teórica, o que impede que os alunos vivenciem diferentes modalidades do exercício da prática clínica. 
Do ponto de vista da instituição, diversas universidades direcionam para um atendimento clínico e às vezes impedem certas modalidades na formação clínica, dificultam certas modalidades na formação. Acho que é preciso muitas vezes lidar com essas limitações do aprendizado clínico, o que não significa o avesso, ou seja, pensar que ele é limitador demais e que nada acontece. (D3)

Zabalza (2004), ao discutir sobre o ensino superior, chama a atenção para a necessidade de tomarmos consciência da importância do contexto político-acadêmico em que cada instituição de ensino está inserida, pois este irá influenciar no modelo de profissional que cada instituição irá formar.

A proposta curricular pode ainda ficar prejudicada pelas condições de "infra-estrutura institucional". Nesses casos, a redução de carga horária dos atendimentos práticos pode acontecer em decorrência de limitação do espaço físico: "Há um grande problema pensando em aumento de horas na clínica para melhorar a formação do aluno. Há o problema real de espaço físico, o que impossibilita o aumento da carga horária" (D5).

A postura docente frente aos alunos da área de Psicologia clínica pode também gerar dificuldades no ensino: "A gente está conversando sobre pessoas que estão preparadas para ajudar o outro. Eu acho que isso é um pouco deficiente, porque tem pessoas que você vê que não têm nada a ver, não têm perfil para orientar os alunos" (P6).

É apontada a incompreensão de alguns docentes e supervisores quanto aos objetivos da graduação em Psicologia, "enfatizando a especialização" nesse nível de ensino.

A gente vê psicanalistas dando aula, com a idéia de que vão formar psicanalistas dentro de um curso de graduação. Isso eu acho um grande equívoco na formação do psicólogo. Não dá para formar o psicanalista, então é preciso que se detenha um pouco mais em como seriam os conceitos básicos da psicanálise, o princípio, qual o propósito da psicanálise e quais as contribuições da psicanálise para o psicólogo em geral. (D3)

A atuação do professor de ensino superior que contribuirá para a formação de novos profissionais tem muita relevância, pois é em função dessa atuação que poderá haver a facilitação ou não da aprendizagem do aluno. Isso demanda um esforço de conhecimento, de pesquisa e de avaliação.

Segundo Masetto (1998), os cursos de graduação que ainda mantêm o estilo tradicional de ensino não enfatizam a pesquisa, mantendo uma organização curricular fechada com quase nenhuma abertura para a interdisciplinaridade.

As Diretrizes Curriculares Nacionais dos Cursos de Graduação (CNE/CES, 1999) explicitam, em um de seus princípios, que os professores devem "encorajar o reconhecimento de conhecimentos, habilidades e competências adquiridas fora do ambiente escolar, inclusive as que se refiram à experiência profissional julgada relevante para a área de formação considerada".

Para Mancebo (1998), as políticas governamentais na atualidade visam "à formação para a aquisição de competências" (p. 54). Um docente não familiarizado com a idéia de que a formação, na atualidade, é vista como um processo que perdura toda a vida, continuará entendendo-a "como um bloco que se dá em um período curto de tempo (duração do curso)" (Zabalza, 2004, p. 28). Segundo o autor, as mudanças ocorridas na universidade e a pressão por qualidade exigem do docente a revisão de seus enfoques e de suas estratégias de atuação. Em função disso, surgem algumas repercussões para os professores de ensino superior, como: "atividades de assessoramento e apoio aos 
estudantes, ... desenvolvimento e supervisão de atividades de aprendizagem em distintos ambientes de formação" (pp. 30-31).

Os sujeitos percebem que existe uma "carência no processo de profissionalização docente" na área. Alguns professores demonstram uma fragilidade na capacidade de atuar como professor e/ou supervisor, e os entrevistados destacam que isso contribui para as dificuldades encontradas durante sua inserção na prática.

Eu acho que algumas vezes o próprio docente, as pessoas dentro da universidade que trabalham com alunos, não sabem como fazer com os alunos. Esse professor está preocupado em dar muito conteúdo, porque ele acredita que o aluno precisa desse conteúdo e não dá tempo de dar outras coisas. (P8)

Batista (2005) comenta que a profissionalização docente, na atualidade, é um tema importante em função das mudanças curriculares e metodológicas por que passam os cursos de graduação. Segundo o autor, a prática docente universitária em saúde se torna uma atividade complexa e interdisciplinar.

Na concepção de saúde que tem como referência doutrinária a reforma sanitária e, como estratégia de reordenação setorial e institucional, o SUS, torna-se necessário considerar uma formação de trabalhadores em saúde "inspirada no paradigma da promoção da saúde que aponta a multisetorialidade, de um lado, e a interdisciplinaridade ou transdisciplinaridade, de outro" (Brasil, 1999) .

As diretrizes curriculares mostram um novo caminho para a formação do profissional da área da saúde, prevendo, entre outras questões, a integração de conteúdos e o desenvolvimento de competências e habilidades, a utilização de metodologias ativas de ensino que levem o estudante a aprender a aprender e a compreender a necessidade da educação permanente, a integração do ensino, dos serviços de saúde e da comunidade, aproximando o futuro profissional da realidade social, a articulação entre ensino, pesquisa, extensão e assistência, e, acima de tudo, a formação de profissionais com autonomia e discernimento para assegurar a integralidade da atenção e a qualidade e a humanização do atendimento prestado.

Nesse contexto, em que as mudanças se tornam essenciais para que os cursos atendam a esse novo caminho preconizado pelas DCN, não basta reorganizar currículos tentando integrar os conteúdos ou reescrever o projeto pedagógico. Trata-se de romper a prática pedagógica presente hoje na universidade, que implica reunir a reflexão teórica, a reflexão prática e a ação social. É preciso mudar a construção do conhecimento que está diretamente ligado à prática docente de reprodução e transmissão do conhecimento, fazer com que o docente se reconheça como protagonista das mudanças que se fazem urgentes, isto é, preparar o estudante para aprender a aprender de forma a acompanhar a evolução do conhecimento para interagir com os demais profissionais de saúde, atuando com competência em equipes multidisciplinares a fim de compreender a realidade do Sistema Único de Saúde e, mais do que isso, para refletir sobre ela, buscando atender às necessidades básicas de saúde dos usuários.

As DCNs dos cursos de graduação recomendam que as IES devem "contemplar orientações para as atividades de estágio e demais atividades que integrem o saber acadêmico à prática profissional, incentivando o reconhecimento de habilidades e competências adquiridas fora do ambiente escolar" (Brasil, 2003).

A discussão de Batista (2005) corrobora as novas orientações para a graduação, quando 
esse autor afirma que, em função das transformações atuais do ensino superior, há um novo referencial para a formação docente que "reconhece o professor como um produtor de saber e de saber-fazer" (pp. 288-289). Isso implica a "necessidade de investigar os saberes mobilizados e produzidos pelo professor na sua ação cotidiana" (p. 289).

Zabalza (2004) afirma que o professorformador se situa como mediador nos encontros e experiências formativas, investindo em interações que privilegiam a troca de idéias, nas vivências, na discussão coletiva sobre as práticas, no saber já acumulado pelo grupo e nos movimentos de teorização das ações docentes.

O perfil do aluno ingressante aparece também como uma das dificuldades para o ensino de Psicologia clínica na graduação. Para os entrevistados, o que aparece, de forma marcante como fator de dificuldade é a "imaturidade dos alunos": "Quando a gente é mais jovem, é um momento de vida que a gente não dá conta de assimilar o que a faculdade está proporcionando" (P3).

Na Psicologia, a imaturidade dos alunos pode gerar representações sobre a profissão construídas a partir do senso comum nas relações sociais que estabeleceram até a sua entrada na graduação. Entendemos que essa representação é geralmente elaborada a partir de "estereótipos relacionados ao modelo médico aplicado à Psicologia bem como o modelo 'místico', que dá ao psicólogo o poder de 'cura' dos doentes" (Abdalla, 1999, p. 114).

O aluno que chega com esse tipo de representação apresenta dificuldade de perceber o psicólogo em sua atuação social. Os professores, e, por extensão, as universidades, devem questionar esses estereótipos para que os alunos possam (re) elaborar suas representações sobre o modelo do profissional de Psicologia e possam, na (re)construção dessa representação, feita socialmente, tomar consciência "da importância da Psicologia na sociedade em que vivemos, da função social do psicólogo nesta sociedade e da pluralidade de opções de atuação desse profissional" (Abdalla, 1999, p. 114).

A "imaturidade" discente reflete, de acordo com Dini e Batista (2004), a trajetória de vida de alunos que chegam à universidade estressados, vindos de um vestibular que, às vezes, é feito em função de pressões familiares ou sociais. Esse aluno, segundo os autores, deve ser bem compreendido pelas escolas, que devem conhecer "suas expectativas, concepções e representações sobre o curso e a prática profissional futura" (p. 199).

Os autores salientam que os docentes na graduação devem, na sua trajetória de formadores de futuros profissionais, perceber que o "desenvolvimento do estudante do ensino superior ocorre em fases, incluindo momentos de estabilidade e transição" (p. 199). No início do curso, o aluno idealiza o modelo de profissional que quer ser e pensa que a escola vai transformálo nesse profissional. No decorrer do curso, essa representação vai sendo substituída por um desencantamento, pois o aluno muitas vezes não compreende a utilidade dos conteúdos apresentados para sua aprendizagem; queixa-se da má didática dos professores e do volume de estudo, e, no final da sua formação, fica ansioso e inseguro quando se depara com as dificuldades da prática profissional.

Esse pensamento vai ao encontro da fala de um dos sujeitos, que reforça a importância da maturidade do aluno para sua formação em Psicologia clínica: "Eu acho que, na Psicologia clínica, precisa de uma maturidade. Acho que essa maturidade leva em conta algumas coisas. Eu levo em conta assim: vivência enquanto pessoa mesmo, enquanto poder ouvir outras pessoas" (P8). 


\section{Considerações finais}

O percurso de pesquisa aqui construído permite afirmar que existe uma mudança de visão e uma desconstrução do que se conceituava como Psicologia clínica. A desconstrução do modelo de clínica a que nos referimos pode ser entendida como uma mudança de paradigma, isto é, uma mudança epistemológica que, no entender de Dutra (2004), deve permitir que o psicólogo clínico considere o sujeito diante dele como aquele que se constitui no mundo numa relação com o mundo natural e social, mundo esse que, ao mesmo tempo em que o constitui, também é constituído por ele.

Essa transição paradigmática traz simultaneamente dificuldades e desafios para o ensino de Psicologia clínica.

No campo das dificuldades, quatro eixos foram apreendidos nesta pesquisa: a complexidade do campo da Psicologia, a dinâmica de supervisão docente, o perfil do aluno e a dimensão curricular.

Identifica-se que esses eixos se imbricam, configurando um panorama que remete, historicamente, à promulgação, em 1996, da Nova Lei de Diretrizes e Bases da Educação (NLDB), portadora de pressupostos fundamentais que parecem corroborar as mudanças sociopolíticoeconômicas evidenciadas no País, fomentando discussões sobre qual profissional se deseja formar para uma contemporaneidade marcada pela preocupação com a ética, com o humanismo, com o conhecimento e com a interdisciplinaridade.

Nesse sentido, pode-se observar que as dificuldades no ensino da Psicologia clínica envolvem as dimensões epistemológicas, políticas, pedagógicas e educacionais, decorrendo desse fato, portanto, desafios relativos a modelos curriculares, constituição dos serviços-escola, inserção dos alunos em diferentes cenários de prática desde o início da graduação, formação dos professores frente às novas propostas educacionais e organização de situações de aprendizagem coadunadas com uma nova concepção do fazer clínico em Psicologia.

No âmbito do currículo em Psicologia, explicitase a necessidade de serem estruturados modelos curriculares potencializadores da inserção do aluno de graduação em Psicologia em um ensino fundado na aprendizagem ativa, voltado também para os serviços de saúde com o objetivo de consolidação do SUS, e que esteja ancorado na construção de vínculos e articulações entre teoria e prática. Seriam currículos comprometidos com a formação de um profissional de Psicologia que trabalhem a subjetividade do outro, não mais como uma experiência individual, mas como uma experiência constituída a partir de condições histórico-culturais, no âmbito de relações interpessoais.

O processo de reconstrução curricular passa, dentre outros condicionantes, pelo desafio de formar espaços de formação docente facilitadores da troca de saberes e de experiência entre os professores, que criem condições para que esses docentes possam refletir sobre suas práticas, analisá-las no contexto das políticas contemporâneas da educação superior, das questões presentes do mundo do trabalho em Psicologia e, ainda, das condições institucionais que marcam um dado curso.

Destaca-se também o desafio da construção de novas formas de trabalho docente no que se refere à supervisão e à estruturação das situações de aprendizagem teórica e prática, com o professor podendo reconhecer a docência em Psicologia como uma profissão complexa e multideterminada. Esse desafio ganha contornos importantes na medida em que se reconhece a relevância da relação entre professor e aluno para a construção da identidade como psicólogo clínico do futuro profissional. 


\section{Ively Guimarães Abdalla*}

Centro de Desenvolvimento do Ensino Superior em Saúde (CEDESS) - Universidade Federal de São Paulo (UNIFESP) - Mestre em Ciências/Unifesp

\section{Sylvia Helena Batista}

Campus Baixada Santista; Centro de Desenvolvimento do Ensino Superior em Saúde (CEDESS) - Universidade Federal de São Paulo (UNIFESP) - Doutora em Psicologia da Educação/PUCSP

\section{Nildo Alves Batista}

Coordenador do Programa de Pós-Graduação Ensino em Ciências da Saúde - CEDESS/UNIFESP - Doutor em Medicina/USP - Livre-docente em Educação Médica/Unifesp - Professor titular de Ensino em Ciências da Saúde/ Unifesp

*Endereço para envio de correspondência:

Alameda dos Arapanés, 628, ap. 91 - São Paulo - SP - Brasil CEP: 04524-001

E-mail: ively.abdalla@unifesp.br 


\section{Referências}

Abdalla, I. G. (1999). Ter equilíbrio para dar equilíbrio. Profissão: Psicólogo? São Paulo: Arte \& Ciência.

Aguirre, A. M. de B., Herzberg, E., Pinto, E. B., Becker, E., Carmo, H. M. S., \& Santiago, M. D. E. (2000). A formação da atitude clínica no estagiário de psicologia. Psicologia USP, 11(1), 49-62. Recuperado em 06 de fevereiro de 2007, de http://www.scielo. br/. Doi: 10.1590/S0103-65642000000100004.

Batista, N. A. (2004). Planejamento na prática docente em saúde. In N. A. Batista, \& S. H. Batista (Orgs.), Docência em saúde: temas e experiências (pp. 35-56). São Paulo: Senac.

Batista, N. A. (2005). Desenvolvimento docente na área da saúde: uma análise. Trabalho, Educação e Saúde, 3(2), 283-294.

Batista, N., Batista, S. H., \& Goldenberg, P. (2005). O enfoque problematizador na formação de profissionais da saúde. Revista de Saúde Pública, 39(2), 231-237.

Brasil. (1996). Lei $n^{\circ}$ 9394, de 20 de dezembro. Estabelece as diretrizes e bases da educação nacional. Recuperado em 14 de fevereiro de 2006, de http:// www.planalto.gov.br/CCIVIL_03/LEIS/L9394.htm

Brasil. Ministério da Educação. Ministério da Saúde. Organização Pan-Americana da Saúde. (1999). Diretrizes curriculares nacionais para o ensino técnico: área da saúde. Brasília, DF: Autor. Recuperado em 24 de maio de 2005, de http://www.bvseps.epsjv. fiocruz.br/html/pt/DiretrizesCurric.Nac.paraEnsinoT \%E9cnico\%C1readeSa\%FAde1999.pdf

Brasil. Conselho Nacional de Educação. Câmara de Educação Superior. (2003). Parecer do CNE/CES n 67, aprova referencial para as Diretrizes Curriculares Nacionais - DCN - dos cursos de graduação e propõe a revogação do ato homologatório do Parecer CNE/ CES $n^{\circ}$ 146/2002. Recuperado em 14 de fevereiro de 2006, de http://portal.mec.gov.br/cne/arquivos/ pdf/CES0067.pdf

Brasil. Conselho Nacional de Educação. Câmara de Educação Superior. (2004). Resolução $n^{\circ}$ 8, de 7 de maio, institui as Diretrizes Curriculares Nacionais para os cursos de graduação em Psicologia. Recuperado em 01 de setembro de 20024, de http://portal.mec. gov.br/cne/arquivos/pdf/CES0067.pdf

Dini, P. S., \& Batista, N. A. (2004). Graduação e prática médica: expectativas e concepções de estudantes de Medicina do $1^{\circ}$ ao $6^{\circ}$ ano. Revista Brasileira de Educação Médica, 28(3), 198-203.
Dutra, E. (2004). Considerações sobre as significações da psicologia clínica na contemporaneidade. Estudos de Psicologia (Natal), 9(2), 381-387.

Ferreira Neto, J. L., \& Dias Penna, L. M. (2006). Ética, clínica e diretrizes: a formação do psicólogo em tempos de avaliação de cursos. Psicologia em Estudo, 11(2), 381-390.

Franco, M. L. (2003). Análise do conteúdo. Brasília, DF: Plano.

Gioia-Martins, D., \& Rocha Junior, A. (2001). Psicologia da saúde e o novo paradigma: novo paradigma? Psicologia: Teoria e Prática, 3(1), 35-42.

Lo Bianco, A. C., Bastos, A. V. B., Nunes, M. L. T., \& Silva, R. C. (1994). Concepções e atividades emergentes na Psicologia clínica: implicações para a formação. In Conselho Federal de Psicologia (Ed.), Psicólogo brasileiro: práticas emergentes e desafios para a formação (pp. 7-76). São Paulo: Casa do Psicólogo.

Mancebo, D. (1998). Políticas para a educação superior e a formação profissional. Revista Paulista de Psicologia e Educação, 1, 47-65.

Masetto, M. (Ed.). (1998). Docência na universidade. Campinas, SP: Papirus.

Minayo, M. C. S. (1999). O desafio do conhecimento. Pesquisa qualitativa em saúde (6a ed.). São Paulo: HUCITEC.

Paparelli, R. B., \& Nogueira-Martins, M. C. F. (2007). Psicólogos em formação: vivências e demandas em plantão psicológico. Psicologia: Ciência e Profissão, 27(1), 64-79.

Spink, M. J. P. (Coord.), Bernardes, J. de S., \& Menegon, V. S. M. (2006). A Psicologia em diálogo com o SUS: prática profissional e produção acadêmica (Projeto Coletivo de Cooperação Técnica da Associação Brasileira de Ensino de Psicologia - Mudança na Formação em Psicologia e Pesquisa e Sistematização de Experiências). Recuperado em 10 de janeiro de 2007, de http://www.abepsi.org.br/abep/Relatorio_ pesquisa_ABEP.pdf

Zabala, A. (2002). Enfoque globalizador e pensamento complexo: uma proposta para o currículo escolar. Porto Alegre: Artes Médicas.

Zabalza, M. A. (2004). O ensino universitário: seu cenário e seus protagonistas. São Paulo: ARTMED. 